\title{
Research Paper: Effect of Cognitive Behavioral Therapy on Social Competence in Physically Disabled Adolescents
}

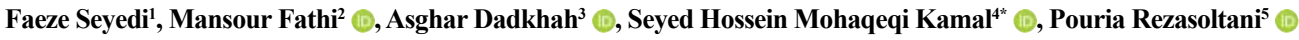 \\ 1. Department of Social Work, University of Social Welfare and Rehabilitation Sciences, Tehran, Iran. \\ 2. Department of Social Work, Faculty of Social Sciences, Allameh Tabataba'i University, Tehran, Iran. \\ 3. Department of Counseling, University of Social Welfare and Rehabilitation Sciences, Tehran, Iran. \\ 4. Social Welfare Management Research Center, University of Social Welfare and Rehabilitation Sciences, Tehran, Iran \\ 5. Medical Sciences Educational Development Center, University of Social Welfare and Rehabilitation Sciences, Tehran, Iran.
}

\begin{tabular}{|l|l|l}
\hline $\begin{array}{c}\text { Use your device to scan } \\
\text { and readthe article online }\end{array}$ & $\begin{array}{l}\text { Citation Seyedi F, Fathi M, Dadkhah A, Mohaqeqi Kamal SH, Rezasoltani P. Effect of Cognitive Behavioral Therapy on } \\
\text { Social Competence in Physically Disabled Adolescents. Iranian Rehabilitation Journal. 2018; 16(4):339-346. http://dx.doi. } \\
\text { org/10.32598/irj.16.4.339 }\end{array}$ \\
doil http://dx.doi.org/10.32598/irj.16.4.339
\end{tabular}

Article info:

Received: 13 Mar 2018

Accepted: 10 Jul 2018

Available Online: 01 Dec 2018

Keywords:

Disabled persons, Adolescents, Social work, Social competence, Cognitive behavioral therapy

\section{A B S T RACT}

Objectives: This study aimed to evaluate the effect of social group work interventions with cognitive behavioral approach on social competence in physically disabled adolescents.

Methods: This was a quasi-experimental study with a pre-test and post-test and control group design. The statistical population included physically disabled adolescents aged 13-18 years who were referred to the Center of Rehabilitation and Vocational Training in Sanandaj City, Iran, to participate in educational programs. To this end, 30 physically disabled adolescents were selected based on inclusion criteria and were divided into 2 matching groups (intervention and control). Social competence questionnaire was completed by both groups at the beginning and at the end of training. The intervention group was trained for 8 weeks in terms of social competence, whereas the control group received no special training. The obtained data were analyzed using SPSS. The Chi-square, Independent samples t-test, and Paired t test were used to verify the study assumptions.

Results: Comparing the intervention group with the controls before and after training reveled that teaching patients with cognitive behavioral strategies had a significant impact on increasing their social competence $(M e a n \pm S D, 181.66 \pm 17.88$ versus $120.93 \pm 10.47 ; \mathrm{P}=0.0001)$ and its dimensions (cognitive, behavioral, emotional and motivational) of the former group.

Discussion: It seems that one of the efficient methods to increase social competence among physically disabled adolescents is cognitive behavioral therapy within the social group work. Thus, coaches and teachers of this group are recommended to use this method, to increase their social competence and subsequently increasing their presence in public areas.

\section{* Corresponding Author:}

Seyed Hossein Mohaqeqi Kamal, PhD.

Address: Social Welfare Management Research Center, University of Social Welfare and Rehabilitation Sciences, Tehran, Iran.

Tel: +98 (21) 22180048

E-mail: hosseinmohaqeq@gmail.com 


\section{Highlights}

- Social competence refers to the quality of peer communication and social behavior in social settings.

- Children's social competence is one of the most important predictors of children's development.

- Adolescents with early problems in social behaviors are at risk for experiencing negative consequences.

\section{Plain Language Summary}

People with disabilities need to adapt with their environment. However, family members of disabled people might take an avoidance attitude, rejection, or too much support that add to already many problems for these people. Disabled people in dealing with these issues may develop negative attitudes, prejudices, discrimination, and maladaptive behaviors. The consequences of these issues are psychosocial barriers and deficiencies in health and social capabilities. Thus, the disabled people have lower self-esteem and self-confidence and in general have less social interactions. Some of these factors can be explained by lower "social competence" in persons with disabilities.

\section{Introduction}

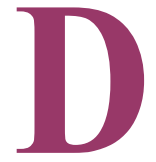

isability goes beyond physical dysfunction and includes activity restrictions, stigma, discrimination, and social participation limitations [1]. The Global Burden of Disease (GBD) has defined disability as the loss of health in areas such as mobility, cognition, hearing, and vision [2]. More than $15 \%$ of the world population suffer from disabilities that restrict their function in family, community, and politics. Eighty percent of them live in low- and middle-income countries [3]. According to the International Classification of Functioning, disability and health (ICF), social stigma and discrimination are considered as significant 'environmental factors' that contribute to disability $[2,4,5]$.

As the National Information Center for Children and Youth with Disabilities (2015) describes, a physical disability is defined as a physical condition that negatively affects at least one main living activity of an individual [6]. People with disabilities need an ability to be compatible and adapt to their environment. Moreover, because of unfavorable attitudes in society, the family members of physically disabled people are avoidant, rejectful, or too much supportive to them, that creates many problems. Once dealing with such issues, disabled individuals may experience negative attitudes, prejudice, discrimination, and maladaptive behaviors that affect various aspects of their lives. The consequences of these issues are psychosocial barriers and deficiencies in health and social capabilities. This leads to lower self-esteem and selfconfidence in this population, compare to other healthy people. It also makes them uncomfortable in social com- munication, ultimately resulting in less social interaction. Some of these factors can be explained by lower "social competence" in persons with disabilities.

Social competence is a basic characteristic of child's psychological adaptation [7]. It refers to the ability to interact positively and get along well with others [8]. In other words, social competence is described by a set of essential social skills to interact well with others and act effectively in peer groups. Children with inadequate social skills are more exposed to various adverse social outcomes in subsequent lifetimes [9]. Children's social competence is among the most important determinants of children's development $[10,11]$. Moreover, adolescents with early problems in social behavior are at risk of negative consequences such as academic failure, peer rejection, and delinquent behavior [12].

In the current study, we conducted Cognitive Behavior Therapy (CBT) to reduce emotional distress and behavioral problems in persons with physical disabilities, in order to increase their social competence. The efficacy of CBT on social work domains is evident by the constant increase in the number of therapists who consider CBT as their preferred approach of practice [13]. In the CBT approach, clients are assumed to participate in their own changing process. CBT is an empowering model [14].

There is a wealth of literature describing positive consequences of CBT in emotional distress and behavioral problems such as anxiety, depression, and aggression [15-17]. However, there is a gap in investigating the positive consequences of CBT with regard to social factors like social competence. On the other hand, various 
studies have reported that social competence can play a substantial role in the social life of disabled persons [18-20]. Thus, this study evaluated the effect of CBT (including assertiveness skills, self relaxation techniques, cognitive restructuring, stress inoculation training, and self-efficacy) on social competence in physically disabled adolescents.

\section{Methods}

\section{Study design}

The study was designed as a pre-test and post-test with a control group and was conducted at a single site (Center of Rehabilitation and Vocational Training) in Sanandaj City, Iran from June to August 2016.

\section{Study participants}

As shown in Figure 1, from the 34 prospective participants recruited from the center of rehabilitation and vocational training, 4 participants were excluded because of not meeting the inclusion criteria. By matching allocation (based on age, gender, education and type of disability), 15 disabled persons were assigned into the intervention group and 15 others into the control group. The inclusion criteria were physically disabled adolescents being 13 to 18 years old, having normal IQ, being educated, and having physical ability to attend the training sessions. The excluding criteria were unwillingness to participate and absence in more than 2 training sessions. The objective and protocol of the study were described to the participants before signing the written informed consent. In addition, one of the physically disabled adolescents, who was close with other members and had a training experience, served as the facilitator in the training sessions.

\section{Intervention plan and study tools}

The tools employed in the current study were demographic data questionnaire and Felner social competence scale [21]. The socio-demographic data questionnaire included data on age, gender, educational level, and disbility type. In addition, Felner social competence scale contained 47 questions in 4 dimensions of cognitive (e.g. sense of responsibility and criti-

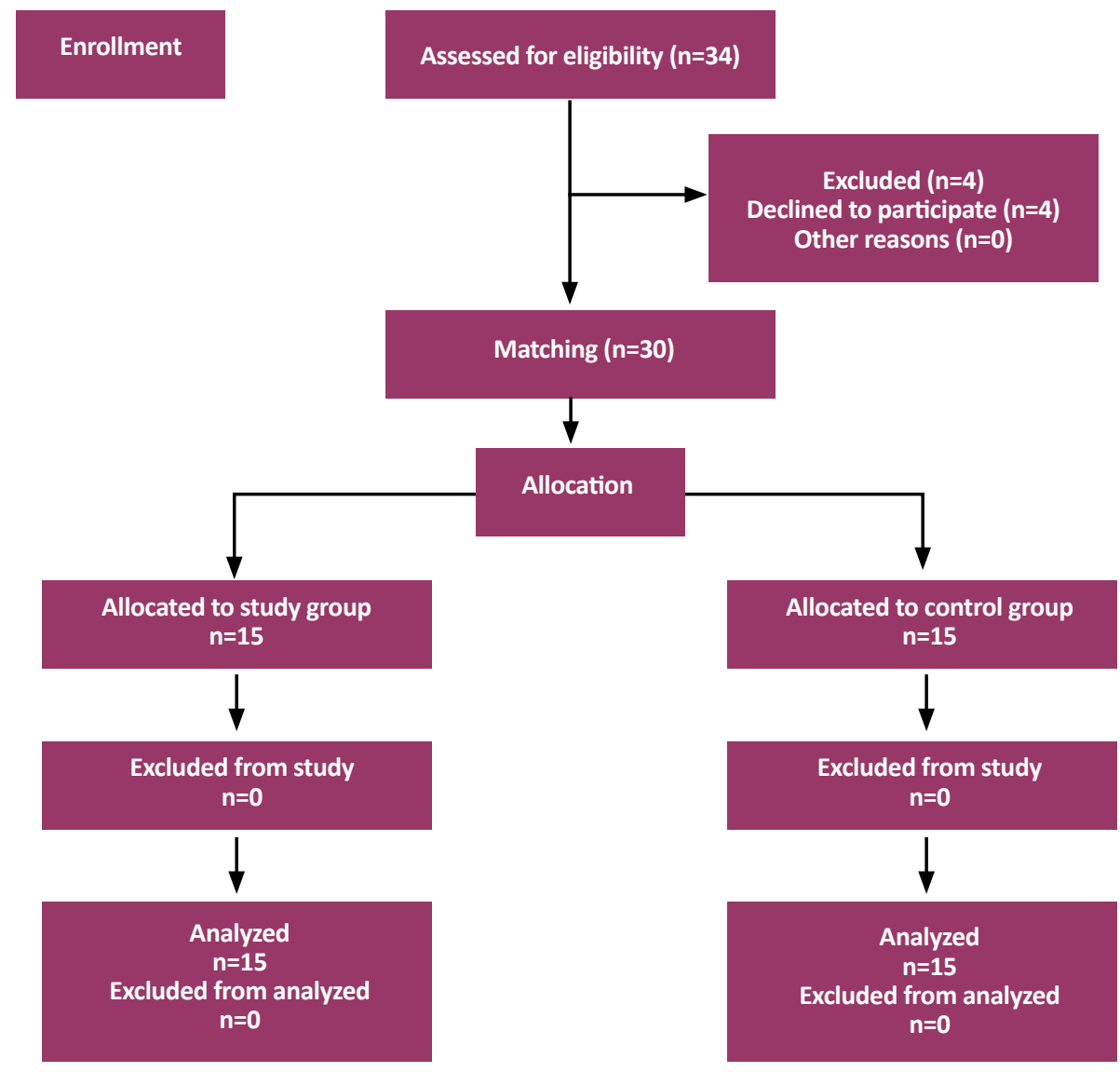

Figure 1. Flowchart of the study 
cal reception), behavioral (e.g. escape from school and completing homework), emotional (e.g. affection for parents and friends), and motivational skills (e.g. doubt in personal abilities and optimism about the future). It had a Likert-type Scale with 7 response options ranging from "strongly agree" to "strongly disagree". The validity and reliability of the questionnaire has been confirmed in previous studies [21, 22].

The social competence questionnaire was completed by the groups both at the beginning and the end of training program. The intervention group was trained for 8 weeks in terms of assertiveness skills, self-relaxation techniques, cognitive restructuring, stress inoculation training, and self-efficacy. The control group received no special trainings. Each session content included the following items:

First week: Creating a positive and supportive relationship among members and the social worker, as well as creating positive impressions among group members. Second week: Promoting trust and group interactions, creating a positive environment for the members, and implementing group activities to enhance member confidence. Third week (skills related to the cognitive dimension): Understanding the efficient and inefficient beliefs when working on issues, educating the participants about cognitive restructuring to change the beliefs and perceptions about problems and inefficient behaviors. Fourth week (skills related to the behavioral dimension): Assertiveness training through role playing exercises. Fifth week (skills related to the motivational dimension): Educating participants about self-efficacy and its stages (self-regulation, succession experiences, and self-talk), and helping members with creating life purpose, and self-regulation. Sixth week: Making progress in training regarding the previous session. Practicing self-talk techniques in a challenging situation. Seventh week (skills related to the emotional dimension): Stress inoculation training, and practicing self-relaxation techniques. Eighth week: Finalizing the teamwork and reviewing the whole process.

All techniques were applied for all 15 participants in the intervention group and in a similar manner. Training sessions lasted 60 minutes and were held once per week. All training sessions were held in the Center of Rehabilitation and Vocational Training in Sanandaj. A trained social worker delivered the intervention sessions. All of the participants completed the treatment protocol. There was no missing data on the intervention sessions.

\section{Data analysis}

The obtained data were analyzed using SPSS. Descriptive statistics including mean and standard deviation scores were computed for all variables. In addition, the Chi-square, Independent samples t-test, and Paired t test were used to verify the study assumptions. The significance level was set at $\mathrm{P}<0.05$.

\section{Results}

According to the demographic findings, the Mean \pm SD age of the intervention and control groups were $15.47 \pm 1.40$ and $15.80 \pm 1.56$ years, respectively. The participants included 8 boys and 7 girls in both groups. In the intervention group, $27 \%$ were educated up to the elementary school, $60 \%$ intermediate school, and $13 \%$ high school. In the control group, $27 \%$ were educated up to the elementary school, $46 \%$ intermediate school, and $27 \%$ high school. In addition, $80 \%$ of participants suffered from congenital disabilities and $20 \%$ were disabled because of accidents (in both groups). In terms of type of disability, $20 \%$ of the participants in the intervention group suffered from ataxia, 47\% from Cerebral Palsy (CP), 13\% from Spinal Cord Injury (SCI), 13\% from amputations, and 7\% from poliomyelitis. While in the control group, $13 \%$ suffered from ataxia, 54\% from $\mathrm{CP}, 13 \%$ from SCI, 13\% from amputations and $7 \%$ from poliomyelitis. According to the Mann-Whitney $\mathrm{U}$ Test and Chi-square Test results, both groups had the same type of disability and educational level. Moreover, no significant difference was observed between the intervention and control groups in terms of demographic data (Table 1).

The results of Independent samples t test were calculated based on the differences between mean scores of social competence and its dimensions in pre-test and posttest, obtained from the intervention and control groups (first P) (Table 2). As a result, the mean score of social competence and its dimensions were higher in the intervention group compared to the control group $(\mathrm{P}=0.001)$.

As presented in Table 2, it is suggested that social group work interventions and CBT had a positive effect on social competence (and its cognitive, behavioral, emotional and motivational dimensions) in the intervention group. In order to confirm the validity of the results, the means score of all 5 main variables were evaluated. According to Table 2, the differences were significant in the intervention group (second $\mathrm{P}$ ). 
Table 1. Demographic information of the intervention and control groups ${ }^{\mathrm{a}}$

\begin{tabular}{|c|c|c|c|c|c|}
\hline \multicolumn{2}{|c|}{ Demographic Factors } & Intervention & Control & Total & $\mathbf{P}$ \\
\hline \multirow{3}{*}{ Gender } & Male & $7(46.7)$ & $8(53.3)$ & $15(50)$ & \multirow{3}{*}{1} \\
\hline & Female & $8(53.3)$ & $7(46.7)$ & $15(50)$ & \\
\hline & Total & $15(100)$ & $15(100)$ & $30(100)$ & \\
\hline \multirow{6}{*}{ Type of disability } & Ataxia & $2(13.3)$ & $3(20)$ & $5(16.7)$ & \multirow{6}{*}{0.761} \\
\hline & Cerebral Palsy & $8(53.3)$ & $7(46.7)$ & $15(50)$ & \\
\hline & Spinal cord injury & $2(13.3)$ & $2(13.3)$ & $4(13.3)$ & \\
\hline & Amputations & $1(6.7)$ & $1(6.7)$ & $2(6.7)$ & \\
\hline & Poliomyelitis & $2(13.3)$ & $2(13.3)$ & $4(13.3)$ & \\
\hline & Total & $15(100)$ & $15(100)$ & $30(100)$ & \\
\hline \multirow{4}{*}{ Educational level } & Elementary school & $4(26.7)$ & $4(26.7)$ & $8(26.7)$ & \multirow{4}{*}{0.438} \\
\hline & Guidance school & $9(60)$ & $7(46.7)$ & $16(53.3)$ & \\
\hline & High school & $2(13.3)$ & $4(26.7)$ & $6(20)$ & \\
\hline & Total & $15(100)$ & $15(100)$ & $30(100)$ & \\
\hline Age, $y$ & Mean $\pm S D$ & $15.47 \pm 1.40$ & $15.80 \pm 1.56$ & $15.64 \pm 1.48$ & 0.652 \\
\hline
\end{tabular}

a: Data are presented in No. (\%) or Mean \pm SD.

Ilranian Rehabilitation Journal

Table 2. Independent samples t-test results of differences between the study variables in the intervention and control groups $(\mathrm{N}=30)$

\begin{tabular}{|c|c|c|c|c|c|c|}
\hline \multirow{2}{*}{ Group } & & \multicolumn{2}{|c|}{ Mean $\pm S D$} & \multirow{2}{*}{$\mathbf{P}^{\mathbf{a}}$} & \multirow{2}{*}{$\begin{array}{l}\text { Mean } \pm S D \\
\text { Difference }\end{array}$} & \multirow{2}{*}{$\begin{array}{l}\mathrm{P}^{\mathrm{b}} \text { [Confidence } \\
\text { Interval] }\end{array}$} \\
\hline & & Pre-Test & Post-Test & & & \\
\hline Social competence & $\begin{array}{c}\text { Intervention } \\
\text { Control }\end{array}$ & $\begin{array}{c}124 \pm 14.16 \\
123.66 \pm 16.85\end{array}$ & $\begin{array}{l}181.66 \pm 17.88 \\
120.93 \pm 10.47\end{array}$ & $\begin{array}{c}<0.001 \\
0.93\end{array}$ & $\begin{array}{l}57.66 \pm 3.72 \\
-2.73 \pm-6.38\end{array}$ & $<0.001[53.89,61.38]$ \\
\hline Cognitive dimension & $\begin{array}{c}\text { Intervention } \\
\text { Control }\end{array}$ & $\begin{array}{l}8.40 \pm 3.60 \\
7.73 \pm 2.52\end{array}$ & $\begin{array}{l}12.46 \pm 2.77 \\
8.40 \pm 2.32\end{array}$ & $\begin{array}{c}<0.001 \\
0.75\end{array}$ & $\begin{array}{l}4.06 \pm-0.83 \\
0.67 \pm-0.20\end{array}$ & $<0.001[3.79,5.89]$ \\
\hline Behavioral dimension & $\begin{array}{c}\text { Intervention } \\
\text { Control }\end{array}$ & $\begin{array}{l}87.20 \pm 13.02 \\
88.93 \pm 12.81\end{array}$ & $\begin{array}{l}132.8 \pm 14.12 \\
88.06 \pm 8.85\end{array}$ & $\begin{array}{c}<0.001 \\
0.14\end{array}$ & $\begin{array}{l}45.60 \pm 1.10 \\
-0.87 \pm-3.96\end{array}$ & $<0.001[44.50,46.70]$ \\
\hline Emotional dimension & $\begin{array}{c}\text { Intervention } \\
\text { Control }\end{array}$ & $\begin{array}{l}8.46 \pm 2.94 \\
8.06 \pm 3.03\end{array}$ & $\begin{array}{l}11.46 \pm 3.16 \\
7.46 \pm 2.32\end{array}$ & $\begin{array}{c}<0.001 \\
0.08\end{array}$ & $\begin{array}{l}3.00 \pm 0.22 \\
-0.6 \pm-0.71\end{array}$ & $<0.001[2.78,3.22]$ \\
\hline Motivational dimension & $\begin{array}{c}\text { Intervention } \\
\text { Control }\end{array}$ & $\begin{array}{l}19.94 \pm 2.71 \\
18.93 \pm 2.49\end{array}$ & $24.93 \pm 4.74$ & $\begin{array}{c}<0.001 \\
0.09\end{array}$ & $\begin{array}{l}4.99 \pm 2.03 \\
-1.93 \pm-1.17\end{array}$ & $<0.001[2.96,7.02]$ \\
\hline
\end{tabular}

$\mathrm{P}^{\mathrm{a}}$ : Test mean score during time by paired sample $\mathrm{t}$-test; $\mathrm{P}^{\mathrm{b}}$ : Test mean score based on the differences between the two groups using student's t-test. 


\section{Discussion}

In this study, the CBT improved social competence among physically disabled adolescents, so that after CBT, social competence significantly improved in the intervention group compared to the controls. This finding is in agreement with the results of similar studies conducted in this field [22-25]. Momeni et al. reported the positive impact of life skills training on enhancement of social and emotional competence in students [22]. It seems that CBT has a positive effect on social competence among physically disabled adolescents. The results also revealed that social work interventions using the CBT had a significant effect on all cognitive, behavioral, emotional, and motivational dimensions among adolescents with physical disability. This finding complies with the results of some studies such as Evans and Allze, Jansson et al. and Hronis et al. For example, Evans and Allze (2018) demonstrated that CBT decrease the client's feelings of anger and increase their self-esteem [26-28].

Previous studies have mainly focused on the role of CBT in reducing psychological and behavioral problems in the normal population. However, the current study focused on the effect of CBT on social competence in physically disabled adolescents.

There are not sufficient supportive recourses in the developing countries to address the needs of people with disabilities. In addition, disabled people face more social stigma in these countries and are seldom present in public areas. Therefore, applying assertiveness, self-relaxation, cognitive restructuring, stress inoculation, and self-efficacy techniques as a social group work intervention can be an effective way to promote the social competence. It could subsequently increase their attendance in educational and occupational fields. Therefore, social workers and professionals are recommended to benefit from these trainings to support physically disabled persons.

Although this study has accomplished its goals, a number of limitations need to be noted. The lack of a follow-up measure to examine whether the results are maintained in the future was among the main limitations. Another limitation in this study relates to the lack of standard training programs for social group work in physically disabled persons.

Further study should focus on the social dimensions of disabilities in order to better know about the effects and dimensions of this issue. Evaluation of the effectiveness of the intervention package introduced in this study with the aim of improving social competence in other groups of adolescents and comparing them with people with disabilities are also suggested. A follow-up evaluation should be conducted to assess the validity of obtained results.

\section{Conclusion}

CBT within the social group work is an efficient method to increase social competence among physically disabled adolescents. Thus, the coaches and teachers of such adolescents are recommended to make use of this technique to increase their social competence and subsequently increase their presence in public areas.

\section{Ethical Considerations}

\section{Compliance with ethical guidelines}

The purpose and protocol of the study was fully explained to the participants and all of them provided a written informed consent. Furthermore, upon completion of the study, the control group received CBT with the same order. The study was approved by the Ethics Committee of the University of Social Welfare and Rehabilitation Sciences (IR.USWR.No.700.240).

\section{Funding}

The present paper was extracted from the MSc. thesis of Faeze Seyedi in Social Work, University of Social Welfare and Rehabilitation Sciences.

\section{Authors contributions}

Study concept and design: Faeze Seyedi, Mansour Fathi, Asghar Dadkhah, Seyed Hossein Mohaqeqi Kamal; Interpretation of data: Poria Reza Soltani, Faeze Seyedi; Manuscript preparation: Seyed Hossein Mohaqeqi Kamal.

\section{Conflict of interest}

The authors declared no conflict of interest.

\section{Acknowledgements}

We deeply appreciate our colleagues in the Center of Rehabilitation and Vocational Training in Sanandaj for their sincere collaboration in the current study. 


\section{References}

[1] Leonardi M, Bickenbach J, Ustun TB, Kostanjsek N, Chatterji S. The definition of disability: What is in a name? The Lancet. 2006; 368(9543):1219-21. [DOI:10.1016/S0140-6736(06)69498-1]

[2] World Health Organization. International Classification of Functioning, disability and health (ICF). Geneva: World Health Organization; 2017.

[3] Fellinghauer B, Reinhardt JD, Stucki G, Bickenbach J. Explaining the disability paradox: A cross-sectional analysis of the Swiss general population. BMC Public Health. 2012; 12:655. [DOI:10.1186/1471-2458-12-655] [PMID] [PMCID]

[4] Stevelink SA, Van Brakel WH, Augustine V. Stigma and social participation in Southern India: Differences and commonalities among persons affected by leprosy and persons living with HIV/ AIDS. Psychology, Health \& Medicine. 2011; 16(6):695-707. [DOI:1 0.1080/13548506.2011.555945] [PMID]

[5] Van Brakel WH. Measuring health-related stigma-a literature review. Psychology, Health \& Medicine. 2006; 11(3):307-34. [DOI:10.1080/13548500600595160] [PMID]

[6] Disabilities, Opportunities, Internetworking, and Technology (DO.IT). National Information Center for Children and Youth with Disabilities (NICHCY). Washington: Disabilities, Opportunities, Internetworking, and Technology (DO.IT); 2017.

[7] Burt KB, Obradović J, Long JD, Masten AS. The interplay of social competence and psychopathology over 20 years: Testing transactional and cascade models. Child Development. 2008; 79(2):35974. [DOI:10.1111/j.1467-8624.2007.01130.x] [PMID]

[8] Semrud Clikeman M. Social competence in children. Berlin Springer; 2007. [DOI:10.1007/978-0-387-71366-3_3]

[9] Posner MI, Rothbart MK. Developing mechanisms of self-regulation. Development and Psychopathology. 2000; 12(3):427-41. [DOI:10.1017/S0954579400003096]

[10] Eiden RD, Colder C, Edwards EP, Leonard KE. A longitudinal study of social competence among children of alcoholic and nonalcoholic parents: Role of parental psychopathology, parental warmth, and self-regulation. Psychology of Addictive Behaviors. 2009; 23(1):36-46. [DOI:10.1037/a0014839] [PMID] [PMCID]

[11] Spinrad TL, Eisenberg N, Gaertner B, Popp T, Smith CL, Kupfer A, et al. Relations of maternal socialization and toddlers' effortful control to children's adjustment and social competence. Developmental Psychology. 2007; 43(5):1170-86. [DOI:10.1037/00121649.43.5.1170] [PMID] [PMCID]

[12] Ganesalingam K, Yeates KO, Taylor HG, Walz NC, Stancin T, Wade S. Executive functions and social competence in young children 6 months following traumatic brain injury. Neuropsychology. 2011; 25(4):466-76. [DOI:10.1037/a0022768] [PMID] [PMCID]

[13] González Prendes AA, Hicks LM, Matthews Th, DomkeS. Cognitive behavioral therapy in social work. In: Mullen EJ, editors. Social Work . Oxford: Oxford University Press; 2012.

[14] Dobson D, Dobson KS. Evidence-based practice of cognitivebehavioral therapy. New York: Guilford Press; 2008.

[15] Haby MM, Donnelly M, Corry J, Vos T. Cognitive behavioural therapy for depression, panic disorder and generalized anxiety disorder: A meta-regression of factors that may predict outcome. Australian and New Zealand Journal of Psychiatry. 2006; 40(1):919. [DOI:10.1080/j.1440-1614.2006.01736.x] [PMID]
[16] Hofmann SG, Asnaani A, Vonk IJ, Sawyer AT, Fang A. The efficacy of cognitive behavioral therapy: A review of metaanalyses. Cognitive Therapy and Research. 2012; 36(5):427-40. [DOI:10.1007/s10608-012-9476-1] [PMID] [PMCID]

[17] Hofmann SG, Smits JA. Cognitive-behavioral therapy for adult anxiety disorders: A meta-analysis of randomized placebo-controlled trials. The Journal of Clinical Psychiatry. 2008; 69(4):621-32. [DOI:10.4088/JCP.v69n0415] [PMID] [PMCID]

[18] Joseph JD, Rausch A, Strain PS. Social competence and young children with special needs: Debunking "mythconceptions". Young Exceptional Children. 2018; 21(1):48-60. [DOI:10.1177/1096250615621359]

[19] Romero V, Fitzpatrick P, Roulier S, Duncan A, Richardson M], Schmidt RC. Evidence of embodied social competence during conversation in high functioning children with autism spectrum disorder. PLOS One. 2018; 13(3):e0193906. [DOI:10.1371/journal. pone.0193906]

[20] Noushabadi FR, Adibsereshki N, Sajedi F, Bakhshi E, Rostam $\mathrm{M}$, Syakhaneh S. Social competence of students with learning disability: Advantages of verbal self-instructional package. Iranian Rehabilitation Journal. 2015; 13(1):8-13.

[21] Felner RD, Lease AM, Phillips RSC. Social competence and the language of adequacy as a subject matter for psychology: A quadripartite tri-level framework. In Gullotta TP, Adams GR, Montemayor R, editors. The Development of Social Competence in Adolescence. Thousand Oaks: Sage Publications; 1990.

[22] Momeni S, Barak M, Kazemi R, Abolghasemi A, Babaei M, Ezati F. Study of the effectiveness of social skills training on social and emotional competence among students with mathematics learning disorder. Creative Education. 2012; 3(08):1307-10. [DOI:10.4236/ce.2012.38191]

[23] Bana S, Sajedi F, Mirzaie H, Rezasoltani P. The efficacy of cognitive behavioral play therapy on self esteem of children with intellectual disability. Iranian Rehabilitation Journal. 2017; 15(3):23542. [DOI:10.29252/nrip.irj.15.3.235]

[24] Soleimani Sefat E, Younesi SJ, Dadkhah A, Rostami M. Effectiveness of cognitive behavioral therapy training in reducing depression in visually impaired male students. Iranian Rehabilitation Journal. 2017; 15(2):165-72. [DOI:10.18869/nrip.irj.15.2.165]

[25] Poulsen S, Lunn S, Daniel SI, Folke S, Mathiesen BB, Katznelson H, et al. A Randomized Controlled Trial of Psychoanalytic Psychotherapy or Cognitive-Behavioral Therapy for Bulimia Nervosa. American Journal of Psychiatry. 2014; 171(1):109-16 [DOI:10.1176/appi.ajp.2013.12121511] [PMID]

[26] Evans L, Allez K. Cognitive behaviour therapy for low self-esteem in a person with a learning disability: A case study. Advances in Mental Health and Intellectual Disabilities. 2018; 12(2):67-76 [DOI:10.1108/AMHID-06-2017-0023]

[27] Jansson Fröjmark M, LintonSJ, Flink IK, Granberg S, Danermark B, Norell Clarke A. Cognitive-behavioral therapy for insomnia comorbid with hearing impairment: A randomized controlled trial. Journal of Clinical Psychology in Medical Settings. 2012; 19(2):224 34. [DOI:10.1007/s10880-011-9275-y] [PMID]

[28] Hronis A, Roberts L, Kneebone II. A review of cognitive impairments in children with intellectual disabilities: Implications for cognitive behaviour therapy. British Journal of Clinical Psychology. 2017; 56(2):189-207. [DOI:10.1111/bjc.12133] [PMID] 
This Page Intentionally Left Blank 